\title{
A Sensor-based System for Monitoring Hard-shoulder Incursions: Review of Technologies and Selection Criteria
}

\author{
Paraskevi Michalaki ${ }^{1}$, Mohammed Quddus ${ }^{1}$, David Pitfield ${ }^{1}$, Mark Mageean ${ }^{2}$ and Andrew Huetson ${ }^{2}$ \\ ${ }^{1}$ School of Civil and Building Engineering, Loughborough University, Loughborough, Leicestershire LE11 3TU, UK \\ ${ }^{2}$ Connect Roads, Balfour Beatty, Spen Common Lane, Tadcaster LS24 9NS, UK
}

\begin{abstract}
According to safety observations from motorway operators in the United Kingdom, the hardshoulder is occasionally violated by road users travelling in the nearside lane. These unintentional movements (hard-shoulder incursions) can impose risk to operatives performing activities on the network. To further investigate these events, a sensor-based system can be used for monitoring them and collecting related data such as severity of incursion and vehicle classification. A review of vehicle detection technologies that could be applied for this purpose is presented, along with the criteria for selection of the most suitable technology and implementation sites. Two potential non-intrusive systems are also described, a laser- and a radar-based systems, which provide different levels of flexibility and data.
\end{abstract}

\section{Introduction}

The hard-shoulder of a motorway is normally used by the public in the event of an emergency or by emergency services as a through route to incidents. The hardshoulder is also used for_operation and maintenance activities. Thus, vehicles of motorway operators often remain on this lane for short durations whilst personnel perform work under live traffic conditions. Even though interest has been raised on the risk of having an accident on the hard-shoulder [1-7], this has not been investigated through rigorous research.

Safety observations from motorway operators in the UK have shown that vehicles travelling on the nearside lane of the main carriageway on occasion violate the hard-shoulder (Fig. 1). Considering that this could occur at any time an operator or emergency vehicle is on the hard-shoulder, it is important to investigate and further understand these events in order to reduce exposure under high-risk conditions. The aim of this study is to review the existing technologies that could be used to track hardshoulder incursions and the criteria used for the selection of a system for this purpose.

To collect data of hard-shoulder incursions, a system installed on the network would need to fulfil the following goals: detecting, measuring, identifying and recording/storing incursion-related data.

- Detecting: The system needs to detect the violations of the raised rib edge-line of the main carriageway (commonly referred to as 'rib-line'), which is the line separating the hard-shoulder from adjacent nearside running lane. These violations are caused by vehicles that are not positioned in the middle of the lane and move onto the hard-shoulder while crossing the rib line. These violations are considered to be inadvertent, unless the road user intends to stop on the hard-shoulder in the case of an emergency or vehicle breakdown.

- Measuring: While detecting hard-shoulder incursions, the system should also measure the severity of incursion, which can be defined by the width (D) and the length (L) of the violation (Fig. 2). The width of an incursion represents how far over the rib-line the vehicle has transgressed. Having the trajectory of the vehicle could provide this information, as well as the length which the vehicle travelled over the rib-line.

- Identifying: In order to explore high risk driver groups, these incursions need to be linked to the identity of the vehicle, i.e. the classification of the vehicle and its speed. The classification of the vehicles is in two main categories (e.g. car or truck) or in multiple categories (e.g. car, van, bus, small truck, large truck, transporter or caravan). There are several methods of classifying vehicles, such as number of axles and space between them, total length/ size of the vehicle and vehicle weight.

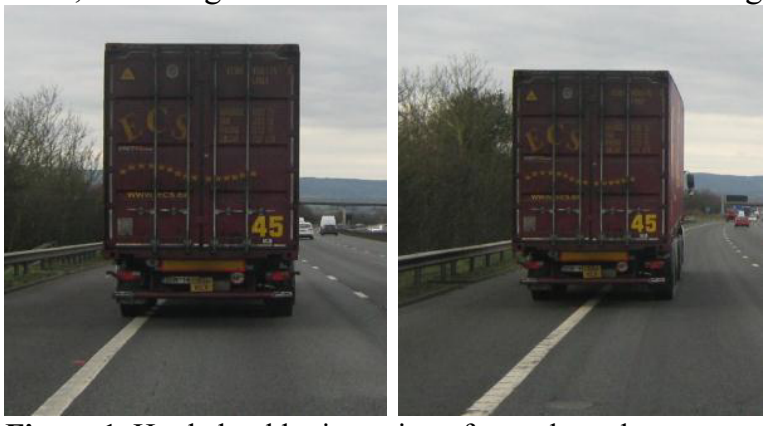

Figure 1. Hard-shoulder incursion of a truck on the motorway (slight/serious). (Source: P. Michalaki) 


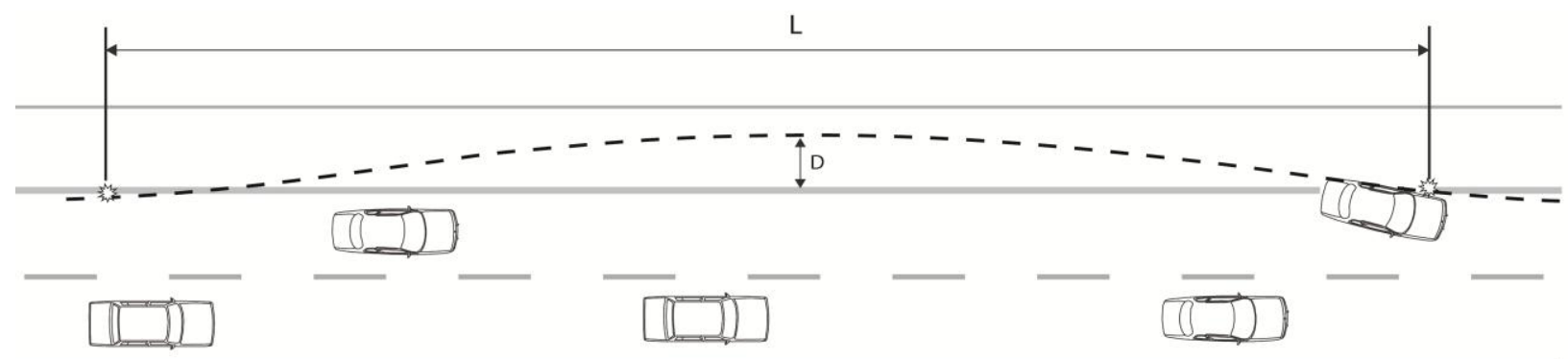

Figure 2. An illustration of a hard-shoulder incursion. (Source: P. Michalaki)

The speed of the vehicle, according to the technology used, might be directly measured or estimated.

- Recording and storing: Finally, all raw data received by the system must be recorded and stored to be readily available for further review and analysis.

\section{Review of technologies}

In this section, potential sensor-based technological solutions for setting up a hard-shoulder incursions monitoring system are discussed, along with the advantages/disadvantages of each (Table 1).

\subsection{Intrusive and non-intrusive technologies: advantages and limitations}

The main categorisation of vehicle detection and traffic counting technologies is in two groups: intrusive and non-intrusive devices. The distinction is based on the level of disruption to normal traffic and the road, as well as the risk to the operator while installing, operating and maintaining the equipment. By definition, non-intrusive devices do not require installation in or on the road. Thus, intrusive devices tend to be permanently installed, while non-intrusive are preferable in temporary, short-term surveys. Both types of technology present several advantages and drawbacks. According to the purpose of the survey, the conditions under which this is performed and the requirements of the motorway operator, it can be decided which device would be most appropriate. Some aspects of these devices are discussed below:

- Safety: Safety of road workers and the public is a key priority. As there is little or no direct interaction with live traffic, non-intrusive devices are generally safer to install. In addition, as the pavement is not disrupted, the carriageway is not adversely affected. However, overroadway sensors in specific, which are mounted over traffic lanes, can disrupt traffic and pose a safety risk to the installers as the installation may require for vehicles to be parked on the road.

- Security: A concern for non-intrusive devices is security. As they can be installed at the side of the carriageway, they are exposed to risk of accidental damage or vandalism. To secure the equipment against damage or theft, the operator must keep workers informed and updated about the presence and scope of the equipment as well as protect it against theft.

- Portability: Due to the way intrusive devices are fixed on a network (e.g. under the pavement), they do not allow for easy transfer from site to site, which may be a requirement especially due to cost constraints, while nonintrusive can be more flexible.

Table 1. Advantages and disadvantages of sensor devices.

\begin{tabular}{|c|c|c|c|}
\hline \multirow{2}{*}{\multicolumn{2}{|c|}{ Sensor type }} & \multicolumn{2}{|c|}{ Characteristics } \\
\hline & & + & - \\
\hline \multirow{4}{*}{ 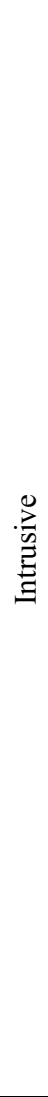 } & $\begin{array}{l}\text { inductive } \\
\text { loop }\end{array}$ & $\begin{array}{l}\text { Well established. } \\
\text { Insensitive to weather. } \\
\text { Flexible design. }\end{array}$ & $\begin{array}{l}\text { Does not provide } \\
\text { information on the exact } \\
\text { position of the vehicle. }\end{array}$ \\
\hline & $\begin{array}{l}\text { pneumatic } \\
\text { road tube }\end{array}$ & $\begin{array}{l}\text { Low acquisition cost. } \\
\text { Easy to install even } \\
\text { though intrusive. }\end{array}$ & $\begin{array}{l}\text { May be displaced } \\
\text { resulting in loss of data. } \\
\text { Snow plows can } \\
\text { damage road tubes. If } \\
\text { installed in a } \\
\text { perpendicular direction } \\
\text { to the traffic, the } \\
\text { severity of incursion } \\
\text { cannot be measured. A } \\
\text { parallel installation is } \\
\text { examined as an } \\
\text { alternative. }\end{array}$ \\
\hline & $\begin{array}{l}\text { piezo- } \\
\text { electric }\end{array}$ & $\begin{array}{l}\text { It measures weight and } \\
\text { speed. }\end{array}$ & $\begin{array}{l}\text { Does not provide } \\
\text { information on the exact } \\
\text { position of the vehicle. } \\
\text { Requires working } \\
\text { within the traffic lane } \\
\text { and is time consuming. } \\
\text { If placed on road } \\
\text { surface, may be } \\
\text { displaced resulting in } \\
\text { loss of data. }\end{array}$ \\
\hline & magnetic & $\begin{array}{l}\text { Insensitive to weather. } \\
\text { Ease of deployment. }\end{array}$ & $\begin{array}{l}\text { Difficulty in } \\
\text { discriminating } \\
\text { longitudinal separation } \\
\text { between closely spaced } \\
\text { vehicles. }\end{array}$ \\
\hline \multirow{3}{*}{ 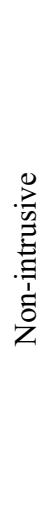 } & infrared & $\begin{array}{l}\text { Accurate measurement } \\
\text { of vehicle position and } \\
\text { speed. Multiple lane } \\
\text { operation available. }\end{array}$ & $\begin{array}{l}\text { Operation may be } \\
\text { affected by low } \\
\text { visibility. Installation } \\
\text { and maintenance require } \\
\text { lane closure. Requires } \\
\text { regular maintenance. } \\
\text { High cost. }\end{array}$ \\
\hline & radar & $\begin{array}{l}\text { Insensitive to weather. } \\
\text { Direct measurement of } \\
\text { vehicle speed. }\end{array}$ & $\begin{array}{l}\text { High cost. Side-fire } \\
\text { installation classifies } \\
\text { vehicles based only on } \\
\text { length. }\end{array}$ \\
\hline & ultrasonic & Low cost. & $\begin{array}{l}\text { It can be affected by } \\
\text { environmental } \\
\text { conditions. }\end{array}$ \\
\hline
\end{tabular}


- Cost: Due to traffic management and increased labour, the cost of installing intrusive devices is generally higher. In addition, due to the lack of portability, the amount of locations where the devices can be permanently fixed is reduced.

- Environmental conditions: Both intrusive and nonintrusive devices can be affected by environmental conditions, though not always in the same way. Thus, intrusive devices, such as piezo-electric cable, are more sensitive to wet road conditions, as well as snow and frost. On the contrary, non-intrusive devices, such as cameras, tend to be affected by low visibility (e.g. fog).

\subsection{Examples of intrusive technologies}

\subsubsection{Inductive loops}

Inductive loops are one of the most common vehicle detection and traffic counting methods used worldwide [8]. An inductive loop system consists of a cable, which is embedded into or under the roadway in a roughly square configuration, a cable extension and a counting device placed on the side of the road $[9,10]$. The loop is based on the principle that a magnetic field introduced near an electrical conductor causes an electrical current to be induced. A metal vehicle passing over the loop acts as the magnetic field and the inductive loop as the electrical conductor [10]. The data supplied by conventional inductive loop detectors are vehicle presence, classification, count and occupancy. Loops cannot directly measure speed; however this can be estimated using a difference loop configuration [11].

Advantages of the inductive loops are its well-known and understood operation as it is mature technology. Also, the equipment cost is relatively low in comparison to other sensor technologies. The same does not apply though to the life-cycle cost of the sensors, as the installation cost is significant. Also, the installation and repair require disruption of traffic and the carriageway pavement. The wire loops are also subject to the stresses of traffic and temperature [8]. In addition, for this study a new configuration would need to be set up, as the existing loops in their normal set-up would not be able to detect incursions.

\subsubsection{Pneumatic tubes}

Pneumatic road tube technology uses hollow rubber tubes to detect vehicles by the change in air pressure generated when a vehicle tyre (or one axle) passes over a tube [12, 13]. The road tube is normally installed across traffic lanes, perpendicular to the traffic flow direction [11]. A device is placed at the side of the road and while connected to the tubes, it records the vehicle axles by the change in pressure. When activated, the device notes the time of the event $[12,13]$. The pneumatic road tube sensor is portable, using rechargeable batteries as a power source [11].

There are several road tube configurations that can be used by a counter depending on the number of lanes and the data needs [12]. Axle counts can be converted to count, speed, and/or classification depending on how the configuration is structured [13]. Looking at the pattern of the compression times (for instance, the time interval between two activations of the counter caused by a vehicle's axles), each compression event is matched to a specific vehicle based on a set vehicle classification scheme. Two tubes attached to the same counter placed a set distance apart on the carriageway can determine the vehicle speed by measuring the time interval between an axle hitting the first and second tubes.

Advantages of pneumatic tube sensors are the low power consumption and the quick installation; this however, requires some intrusion into the flow of traffic $[13,14]$. Road tube sensors are usually low cost and simple to maintain. Sensor manufacturers often supply software packages to assist with data analysis. Disadvantages include limited lane coverage and inaccurate axle counting when multiple axle vehicles' volumes are high or when vehicles are travelling at low speed and/or high proximity. Also, accuracy is subject to weather and temperature conditions $[10,11,12]$.

For this study, the tubes could either be installed on the hard-shoulder perpendicularly to the traffic flow direction, as normal, or alongside the traffic flow, on the rib-line. In both cases, only one, or the two nearside tyres, would be detected, which could affect the classification and speed estimation. In addition, in the second configuration, the risk of the tubes being detached from the pavement due to traffic (and especially trucks) would be higher. Traffic management would be required for the installation and maintenance of pneumatic tubes (closure of the nearside traffic lane).

\subsubsection{Piezoelectic}

These sensors convert kinetic energy to electrical, generating a voltage when subjected to mechanical impact or vibration. The voltage is proportional to the vehicle weight [11]. Piezoelectric sensors can also classify vehicles by axle count and axle spacing and measure vehicle speed, when multiple sensors are deployed. Piezo-electric sensors can either be imbedded in the roadway, which requires cutting into the pavement surface, or placed on the road surface [13]. An advantage of this technology is the differentiation of individual vehicles axles with high precision. However, the accuracy of sensors is subject to pavement temperature and vehicle speed. As with pneumatic tubes, they can be displaced if on the road surface, while these can also fail due to poor road surface [11].

\subsubsection{Magnetic}

Magnetic sensors indicate the presence of a metallic object by the disruption it causes in an induced (active) or natural (passive) magnetic field [15]. The vehicle detection criterion is for the voltage to exceed a predetermined threshold. In order for the sensor to detect the change in the magnetic field, it must be relatively close to the vehicles; thus it is normally installed under or on top of the pavement. Magnetic sensors can be used to 
collect count, speed, and classification data; however, in operating conditions the sensors have difficulty differentiating between closely spaced vehicles $[10,13]$ and generally cannot detect the perimeter of a vehicle accurately, which is a requirement for this study. An advantage of the magnetic detectors in comparison to the inductive loops is that they cause less disruption on the road as they cover a smaller area. Also, they are less sensitive to stresses of traffic [11].

\subsection{Examples of non-intrusive technologies}

\subsubsection{Infrared}

There are two types of infrared technology: active and passive. The former is a device emitting a laser beam at the road surface, measuring the time for the reflected signal to return. The transmitted beam is interrupted by the vehicles, thus the reduction in time indicates this presence. The mounting position for active infrared sensors can vary from over the lane to roadside. Active infrared sensors can potentially provide information on the presence, the volume, the length, the speed and the number of axles. If the laser wavelength is between $400 \mathrm{~nm}$ and $700 \mathrm{~nm}$, the beam is visible to the human eye and the sensor is called visible red light. The second infrared sensor type (passive) does not emit energy of its own and detects a vehicle by measuring infrared energy radiating from the detection zone. The infrared energy naturally emanating from the road surface is compared to the energy radiating when a vehicle is present. Passive infrared detectors are typically mounted over the traffic lane (e.g. on a gantry or bridge) or alternatively on a pole at the roadside. Both active and passive infrared devices can be used to record count, speed, and classification data and work well under day and night conditions. The main drawbacks are the performance during bad weather, and limited lane coverage $[8,10,13]$.

\subsubsection{Radar}

Radar (RAdio Detection And Ranging) technology detects distant objects and is able to determine their position and speed. With vehicle detection, a device transmits high frequency radio waves at the roadway to determine the time delay of the return signal, thereby calculating the distance to the detected vehicle. In opposition to magnetic sensors, radar can also detect stationary vehicles, while at the same time, it can provide, if preferable, all the vehicle information per section of the detection area. An advantage of the radar is its insensitivity to inclement weather conditions and its capability to operate during day and night. $[8,13]$. The radar sensor may be mounted over the carriageway (for single-lane monitoring) or at the side, off the hardshoulder (for detection across several lanes). Sidemounted radars provide data corresponding to several traffic lanes, though generally not as accurately as in the over-looking position. However, side-mounted radars have also been used for single-lane detection [8].

\subsubsection{Ultrasonic}

The ultrasonic sensors transmit sound waves at a selected frequency between 20 and $65 \mathrm{kHz}$, to detect vehicles by measuring the time for the signal to return to the device. The preferred configurations for presence sensors are downward and side viewing, while for speed-measuring sensors is forward-looking. The transducers in both presence and speed-measuring devices convert the sonic energy received back into electrical energy that is then processed. Even though the implementation cost is relatively low, a disadvantage of the ultrasonic sensors is that they can be affected by inclement weather (e.g. low temperatures, snow) $[8,10]$.

\section{Criteria for selection of technology}

In order to select the most suitable technology for the hard-shoulder data collection, a series of criteria are applied.

\subsection{Ability to collect data required}

First and foremost, the equipment selected should be able to collect the data required as accurately as possible. Two potential limitations are the influence of vehicle speed and weather conditions. The technology selected must be effective in high speed conditions (the speed limit for general traffic on UK motorways is $70 \mathrm{mph}(112 \mathrm{~km} / \mathrm{h})$ and $56 \mathrm{mph}$ for trucks $(90 \mathrm{~km} / \mathrm{h})$ [16]. Other potential issues are vehicles in close proximity, which might not be accurately classified as they are not always recognised as two or more separate vehicles, and stationary or slowmoving vehicles, which cannot be recorded by some technologies.

In terms of the environmental conditions, the performance of some types of technologies is influenced by weather events, such as fog, heavy rain and sub-zero temperatures, all of which are often encountered in the area of study. This also includes the detection of dark objects, which, depending on the abilities of the equipment, may be limited.

\subsection{Cost}

The overall cost of the use of equipment, which influences which type is used, includes the following:

- Procurement: the cost of purchasing/renting the equipment, as well as all the accompanying elements (e.g. data logger, power supply establishment of internet connection for remote data collection).

- Installation: the cost of the equipment to be deployed on the network. It includes the number of manhours, the cost for traffic management (e.g. lane closure) and - if required and the possible interventions to the pavement or the existing infrastructure (e.g. gantries, lighting columns) that need to take place, especially if the technology is intrusive.

- Operation: the cost of the energy consumed by the system and the cost for actions required during operation 
(e.g. manual data collection, systematic cleaning of the equipment).

- Maintenance: this can be divided into the routine and emergency costs; it is the cost (including man-hours) for inspecting and repairing, as well as the cost of any traffic management requirements.

- Replacement/Complete removal: this cost depends on the actions required and the possible repairing that the road or the surrounding infrastructure might need, as, for example, in the case of inductive loops.

\subsection{Installation, operation and maintenance requirements}

It is desirable to have minimum installation, operation and maintenance requirements, as this reduces, apart from the cost, the risk to operatives and disruption for road users. For this, side-fire mounting is preferred to over-head as it is simpler to install (no lane closures required). In this context, it is generally preferable for the equipment to be non-intrusive. This means that it causes minimum disruption to normal traffic and the road. If non-intrusive, the equipment is also portable. This is a major advantage in cases that it is necessary to collect data from several locations and there are financial constraints at the same time (See Table 2).

Table 2. Equipment attributes desirable to the road users and the operator.

\begin{tabular}{|c|c|c|}
\hline & INSTALLATION & $\begin{array}{c}\text { OPERATION - } \\
\text { MAINTENANCE }\end{array}$ \\
\hline 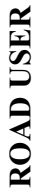 & $\begin{array}{l}\text { Safe installation. } \\
\text { No lane closure or speed } \\
\text { restrictions. } \\
\text { Minimum disruption. }\end{array}$ & $\begin{array}{l}\text { Safe operation and } \\
\text { maintenance. } \\
\text { No distraction to drivers. }\end{array}$ \\
\hline 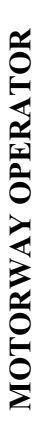 & $\begin{array}{l}\text { Minimum time on the } \\
\text { network for safety and cost. } \\
\text { Minimum disruption to the } \\
\text { public as a good service } \\
\text { should be provided. } \\
\text { No lane closure or Traffic } \\
\text { Management to be installed. } \\
\text { Non-intrusive and/or } \\
\text { portable. } \\
\text { Use of existing } \\
\text { infrastructure as much as } \\
\text { possible. }\end{array}$ & $\begin{array}{l}\text { Minimum maintenance } \\
\text { required. } \\
\text { Reliability (minimum } \\
\text { cost for inspection and } \\
\text { repairs). } \\
\text { Remote data collection. } \\
\text { Energy efficiency. }\end{array}$ \\
\hline
\end{tabular}

\subsection{Health, safety and security}

For equipment to be installed and to operate on the network, health and safety requirements must be met. Generally, when a new piece of equipment is installed, a risk assessment and method statement are prepared to recognise and quantify the risks, mitigate or eliminate them and to determine a safe manner to carry out the installation and ongoing maintenance. Competence is key for health and safety for all phases and training is undertaken if required.

\subsection{Overall}

Overall, it is preferable that the equipment is transferable, i.e. it is possible to move it to another location under different conditions, as it gives the ability to collect data from a greater variety of locations. In addition, if the equipment has been used widely in the past, it means that it should be more reliable and any problems that might appear, as well as the limitations, are generally known. On the contrary, the use of a more contemporary system may offer a better perspective for alternative future uses.

\section{Selection of implementation sites}

In cases where it is not feasible to continuously monitor an area for incursions, mainly due to cost constraints, the sub-sections monitored should be carefully selected in order to cover an extensive variety of conditions, in terms of road construction characteristics (slope, curvature, hard-shoulder/main carriageway lane width, pavement type, street lighting, etc.) and other conditions, if these are known to change significantly (e.g. traffic volume, vehicle classification proportion). Proximity to a junction may also affect driving behaviour. In addition, the resources available on-site are investigated. These include power supply from existing electric cabinets, existing infrastructure that can be used for mounting the equipment (e.g. bridges, gantries), vehicle restraint system (VRS) which provides safer conditions for installation, maintenance and operation. It is also necessary to comply with health and safety legislation and the specification requirements of the Highways England in terms of installing new equipment on the motorway network, including the following:

- Structural Review: A review of an individual or a group of structure (e.g. a bridge or a gantry) to confirm the load carrying capacity. This is conducted when the need arises, such as the installation on additional equipment on the structure, which increases the operational load [17].

- Technical Approval: The submission of a Proposal, the acceptance of which confirms that the design, assessment, specification or construction works complies with the agreed design and specification certificates [18].

- VRS Length of Need: That is the total minimum length of full height, full containment VRS as required in advance of, alongside, and after a hazard to protect this hazard, plus the additional lengths that are declared by the manufacturer to ensure full containment. Thus, any new equipment installed should not affect the VRS' functionality in case of an impact [19].

- Working Width: This is the maximum lateral distance between any part of the barrier and the maximum dynamic position of it. If the vehicle body deforms around the road VRS so that the latter cannot be used for the purpose of measuring the working width, the maximum lateral position of any part of the vehicle is taken as an alternative. The working width need to remain clear from any installations [19].

- $\quad$ Structure Free Zone: This is a buffer zone adjacent to the paved carriageway and beneath a Structure that 
reduces the risk of errant vehicle impacts by providing an appropriate value of headroom [20].

- VRS Set-back: Obstructions immediately adjacent to the edge of the paved carriageway result in drivers reducing speed and positioning their vehicles away from the obstruction. The purpose of the set-back is to provide a lateral distance between the VRS and the carriageway which reduces the effect of the safety barrier on driver behaviour and shyness. Any relaxations must consider the effects on the ability of occupants of stopped vehicles to leave via the nearside doors and the possibility of increased risk due to parking closer to live traffic [20].

\section{Potential hard-shoulder incursions monitoring systems}

After a range of sensors that can be altered to accommodate the study's needs are taken into consideration and the implementation sites are investigated, two potential solutions are suggested: a laser- and a radar-based system. The former is more flexible and easily transferable, while the latter has the potential to provide more detailed information.

\subsection{Laser-based system}

This system comprises of the laser sensors, the data logger and power supply. The laser sensor selected is provided by Micro-Epsilon (ILR1030-15), and has the ability to detect dark objects at a sufficient distance and a measuring frequency high enough to capture high-speed objects (Fig. 3) [21]. The sensors, while mounted at the side of the motorway pointing towards it perpendicularly, are measuring the distance to the overpassing vehicles. Due to the small size of the sensors $(55 \times 26 \times 102 \mathrm{~mm} \mathrm{-}$ 90 grams), they are not considered a risk to road users. As the laser is class 2, it poses no risk in case of eye contact. The sensors are placed inside a standard motorway marker post and are mounted to the rear of the VRS. The marker posts where the laser sensors are installed are additional to the existing ones. The sensors aim at an approximate height of $600 \mathrm{~mm}$ above the carriageway at the outside edge of the rib-line and are levelled when installed.

Campbell Scientific provides a suitable data logger, also of a small size $(241 \times 104 \times 51 \mathrm{~mm}-0.7 \mathrm{~kg})$, to store data from up to three laser sensors (Fig. 4) [22]. The logger has the ability to store data every $10^{-1}$ seconds, which allows the detection vehicles travelling at a speed of $40 \mathrm{~m} / \mathrm{s}$ or $150 \mathrm{kph}(90 \mathrm{mph})$. Using the software provided with the data logger, the device is programmed so as whenever a vehicle crosses the rib-line, the measurement is recorded. The system can be powered either by using a battery, or by connection to the mains (where electric cabinets are present). The laser sensors are connected to and powered via the data logger. In order to protect the cables from damage the cables are carried in ducting.
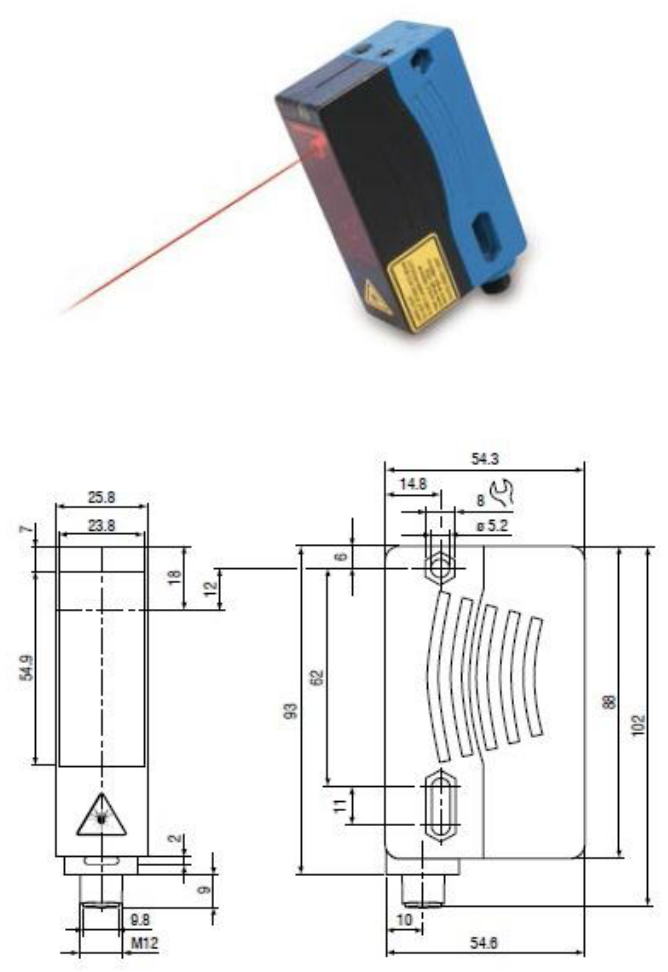

Figure 3. ILR1030-15 Laser sensor by Micro-Epsilon and dimensions (Source : Micro-Epsilon)

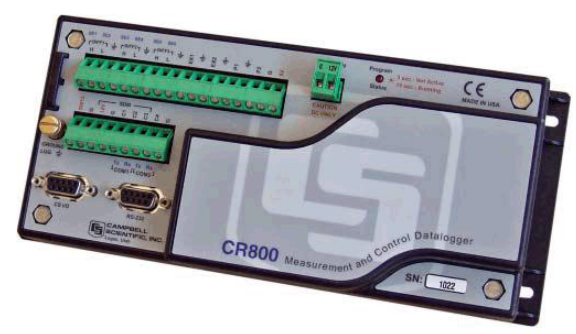

Figure 4. CR800 data logger (Source: Campbell Scientific)

\subsection{Radar-based system}

The alternative suggested method that can provide more detail is radar, which can monitor a continuous section of the motorway. A potential solution is provided by NavTech Radar [23]. The radar sensor is installed at the side of the motorway, while the mounting height can vary between $2 \mathrm{~m}$ and $8 \mathrm{~m}$. For the hard-shoulder monitoring, a minimum height of $2 \mathrm{~m}$ could be applied. However, to ensure security of the equipment, a mounting height of at least $3 \mathrm{~m}$ is preferred. The higher the radar is mounted, the longer distance it can cover, whilst the blind area underneath the radar increases. The radar sensors are positioned to provide the optimum 'line of sight'. In order to check what can be seen by the radar one has to stand at ground level where the radar is mounted, or ideally, at the height of the radar. Whatever is visible to a person is also visible to the radar. Street furniture, such as lamp posts, can create visual obstacles to the radar, especially further away where they appear to be closer together. In a straight line the radar can detect a person located between 20 and $350 \mathrm{~m}$ away, depending on the road geometry and mounting height. 


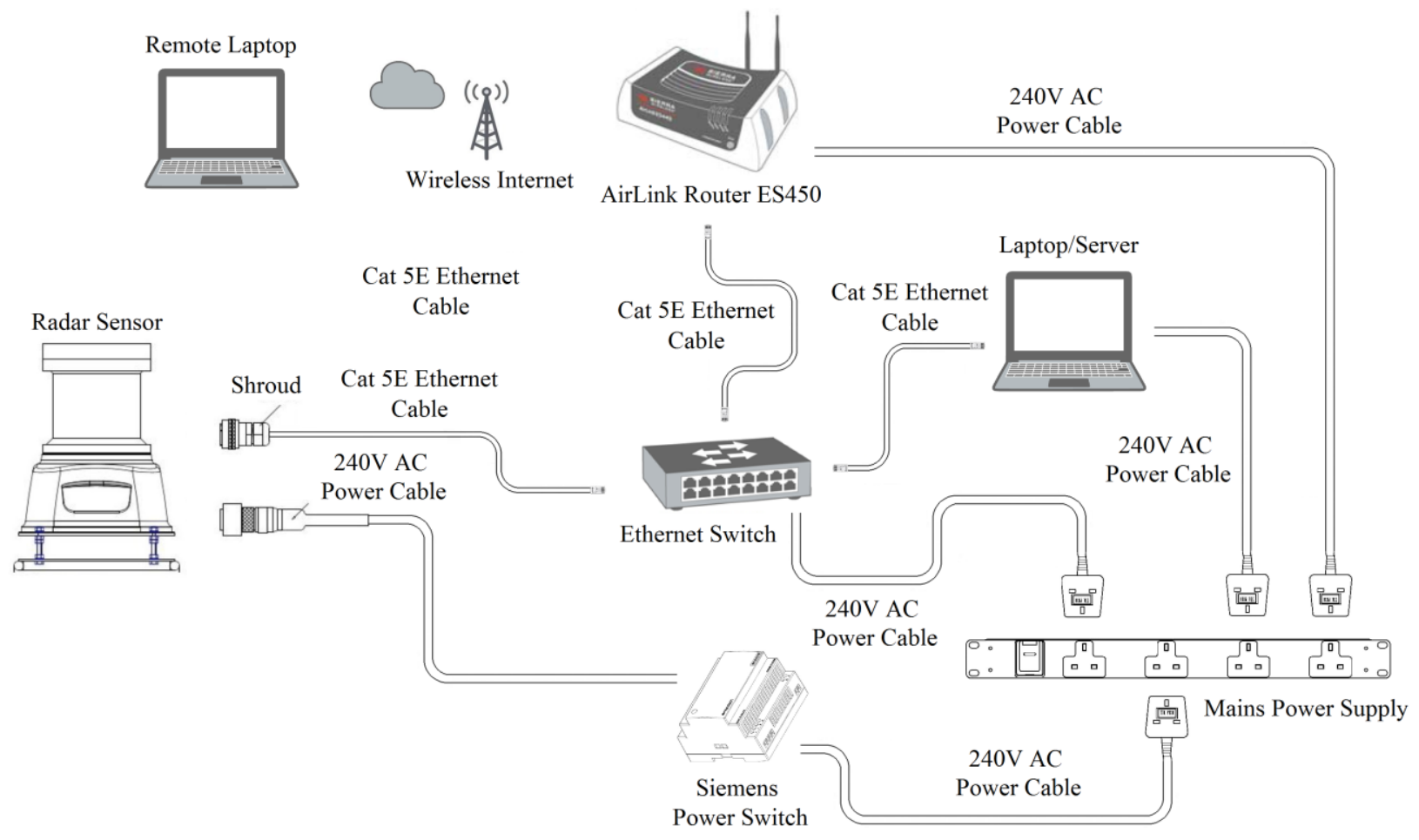

Figure 5. Set up of all the components of the radar system. (Source: P. Michalaki, created using NavTech Radar, Siemens and Sierra Wireless drawings)

The radar sensor may be mounted on dedicated posts, or various other structures - such as walls and gantries using brackets. It is fitted to a plate on top of the post or the bracket using nuts and bolts which allows the tilt adjustment (levelling). On the M1-A1 Link Road, there are a series of structures that could be used for the radar mounting, such as A-Frame concrete gantries, bridges and variable message signs (VMS). While following the requirements of Highways England in the UK, several mounting solutions are investigated:

- Custom-made metal bracket: The bracket can be installed either at the side of an A-Frame gantry support (by drilling and fixing into the concrete) or on its horizontal beam. The main advantages of the metal bracket are the relatively small size, which would not be a distraction to the drivers, and the low manufacturing cost. However, this solution is intrusive to the gantry, would require rectification afterwards, and a full design would be required, which significantly increases the cost. In addition, specialist installation resources and traffic management would be required for the installation of the metal bracket (closure of the hard-shoulder and the nearside traffic lane) resulting in higher disruption for the road user and also higher costs.

- Pole: The manufacturing cost for a pole is considerably higher than that for a bracket and its installation would also require disruptive traffic management, further increasing the cost.

- Trailer Mast System: A trailer system that can be used for mounting the radar sensor is also considered. The approximate dimensions of the trailer are $5.0 \times 2.0 \times 2.0 \mathrm{~m}$ and the approximate weight $500 \mathrm{~kg}$. The extended height can reach up to $15 \mathrm{~m}$. Even though the trailer could operate independently power-wise (solar power facility), which provides more flexibility, its size considerably restricts the locations where it can be used. This solution has higher maintenance requirements as well as certifications for its safety prior to the transfer.

- Scaffold: A scaffold is a temporary structure that can provide a stable base for the radar sensor. This is the solution considered the most suitable for this installation. The base plate is fastened to the scaffold and the radar sensor is positioned on top. The advantage of using a scaffold for this purpose is the non-intrusiveness to the existing structures on the network. In addition, the scaffold is set up 'around' a concrete gantry, thus the structure does not carry any additional weight, but does provide added restraint. In order for the scaffold to be installed, a hard-shoulder closure is required. After the scaffold is set up and the desired height is ensured (around $3.50 \mathrm{~m}$ ) using a simple distance measurement laser, the base plate is secured on top of the scaffold and the radar installed and levelled so it is parallel to the motorway surface. The levelling is achieved by fine adjustment of the nuts and bolts of the base plate. The base plate is first levelled to $0^{\circ}$ and then adjusted according to the motorway slope. After installation access to the scaffold is prohibited to prevent unauthorised use or tampering with the equipment.

Each radar sensor requires a power and data connection via an Ethernet cable. Remote access minimises the necessity for site visits. In order to setup the radar system, several additional components are required. Fig. 5 shows all the connections of the radar system. 
- $\quad$ Power supply: The radar uses 24V DC voltage and is powered via a transformer from the $240 \mathrm{~V}$ AC mains (electric cabinet on-site). The power cable is provided with a military specification connector for the sensor connection and a bare end at the switch connection [24].

- Ethernet connection: An Ethernet cable is connected to the sensor for data transfer. A military specification shroud ensures a suitable environmentally protected network connection. At the other end, the Ethernet cable is connected to an Ethernet switch, which is also powered via the mains supply.

- Laptop/Server connection: A laptop or server is connected to the radar via the Ethernet switch. All components of the radar's software are installed and running constantly on this device, which is required to have certain specifications and is selected accordingly.

- Router connection: In order to have remote access to the laptop/server on-site, a router connection is set up. The IP addresses of all components (router, router's SIM card, on-site laptop/server, remote laptop) are synchronised for the system to function. In order to connect remotely to the laptop/server on-site, remote access software is used [25].

\section{Conclusions}

In this paper, the safety issue of motorway hard-shoulder incursions is approached. Since little is known about how these accidental movements occur, it is crucial to identify methods to monitor them so they can be further investigated. With no working or similar modifiable system available, alternative vehicle detection methods are considered. A review of intrusive and non-intrusive devices provided the advantages and disadvantages of each technology. Looking at the practical whole life process, from procurement and deployment to operation and removal, the considerations in order to employ the most suitable systems were described including basic criteria for equipment and site selection, such as safety, ease of deployment and cost. Based on these factors, two potential systems, a laser-based and a radar-based are suggested. Further research on field tests is being conducted in order to fully evaluate the suitability of each system and gain more feedback on the system parameters and performance.

\section{References}

1. Survive Group, Surviving the Hard Shoulder. (2006) See http://www.survivegroup.org/download_files/Leaflet $\% 2022$ 06-07.pdf (accessed 01/02/2016).

2. Safer Monitoring, Staying Safe on the Hard Shoulder. (2012) See

http://www.safermotoring.co.uk/SafetyOnHardShoulder.html (accessed 01/02/2016).

3. Safer Monitoring, What to do if You Breakdown. (2013) See http://www.safermotoring.co.uk/BreakdownWhatToDo.html (accessed 01/02/2016).

4. Department of Transport, Driver and Vehicle Services, Drive Safe. (2014) Government of Western Australia. See http://www.transport.wa.gov.au/mediaFiles/licensing/LBU_D L_B_DriveSafeFull.pdf (accessed 01/02/2016).
5. ACT - Australian Capital Territory, Road Rules Handbook (2015) See http://www.rego.act.gov.au/_data/assets/pdf_file/0009/56502 9/2015-Road-Rules-Handbook-Accessible-Version.pdf (accessed 05/04/2016).

6. RoSPA - The Royal Society for the Prevention of Accidents, General Driving Policy Statements. (2005) See $\mathrm{http}: / / w w w . r o s p a . c o m / r o a d s a f e t y /$ policy/statements/generaldriving.aspx (accessed 01/02/2016).

7. Brake, Driver advice: vehicle maintenance and breakdowns. (2015) See http://brake.org.uk/info-resources/inforesearch/advice/21-facts-a-resources/resources/291-breakdown (accessed 01/02/2016).

8. L.A. Klein, M. K. Mills, D.R.P. Gibson, Traffic Detector Handbook. Federal Highway Administration, I (2006)

9. MarshProducts, The Basics of Loop Vehicle Detection. (2000).

10. G. Leduc. Road Traffic Data: Collection Methods and Applications. Joint Research Centre, European Commission. (2008)

11. L.E.Y. Mimbela, L.A. Klein, A Summary of Vehicle Detection and Surveillance Technologies used in Intelligent Transportation Systems. (2007)

12. P. McGowen, M. Sanderson, Accuracy of Pneumatic Road Tube Counters. (2011)

13. S.L. Skszek, "State-of-the-Art" Report on Non- Traditional Traffic Counting Methods. Prepared for Arizona Department of Transportation, Phoenix, Arizona. (2001).

14. Smith, D., \& McIntyre, J. (2002). Traffic Volume Counts. In Handbook of Simplified Practice for Traffic Studies. Center for Transportation Research and Education, Iowa State University.

15. L.A. Klein, M.R. Kelley, Detection Technology for IVHS Volume I: Final Report Detection Technology for IVHS, I. (1996).

16. Department for Transport, 2014. Consultation Response Report Examining the Speed Limit for HGVs over 7.5 tonnes on Dual Carriageway Roads: Summary of Responses and Government Response, London.

17. Highways Agency, Transport Scotland, Welsh Government \& Department for Regional Development Northern Ireland, 2011. Design Manual for Roads and Bridges (DMRB) Highway Structures Inspection and Maintenance, 3, Section 4 Part 22 BD 101/11 Structural Review and Assessment of Highway Structures.

18. Highways Agency, Scottish Executive, Welsh Assembly Government \& Department for Regional Development Northern Ireland, 2005. Design Manual for Roads and Bridges (DMRB) Highway Structures: Approval Procedures and General Design, 1, Section 1 Part 1 BD 2/05 Technical Approval of Highway Structures.

19. Highways Agency, Transport Scotland, Welsh Government \& Department for Regional Development Northern Ireland, 2006. Design Manual for Roads and Bridges (DMRB) Highway Structures Design (Substructures \& Special Substructures), Materials, 2, Section 2 Part 22 TD 19/06 Requirement for Road Restraint Systems.

20. Highways Agency, Scottish Executive, Welsh Assembly Government \& Department for Regional Development Northern Ireland, 2005. Design Manual for Roads and Bridges (DMRB) Road Geometry, 6, Section 1 Part 2 TD 27/05 CrossSections and Headrooms.

21. Micro-Epsilon, See http://www.microepsilon.co.uk/displacement-position-sensors/laser-distancesensor/optoNCDT_ILR_1030_1031/index.html

22. Campbell Scientific, See https://www.campbellsci.com/cr800

23. NavTech Radar, See http://www.navtechradar.com/automaticincident-detection

24. Siemens, See http://w3.siemens.com/mcms/power-supplysitop/en/logo-power/pages/default.aspx

25. Sierra Wireless, See https://www.sierrawireless.com/productsand-solutions/gateway-solutions/airlink/ 